\title{
Roadmap Industry 4.0 - Implementation Guideline for Enterprises
}

\author{
Ernst Pessl, Sabrina Romina Sorko, Barbara Mayer \\ Institute Industrial Management, FH JOANNEUM University of Applied Sciences, Kapfenberg, Austria
}

\section{Email address:}

Ernst.Pess1@fh-joanneum.at (E. Pessl), SabrinaRomina.Sorko@fh-joanneum.at (S. R. Sorko), Barbara.Mayer@fh-joanneum.at (B. Mayer)

\section{To cite this article:}

Ernst Pessl, Sabrina Romina Sorko, Barbara Mayer. Roadmap Industry 4.0 - Implementation Guideline for Enterprises. International Journal of Science, Technology and Society. Vol. 5, No. 6, 2017, pp. 193-202. doi: 10.11648/j.ijsts.20170506.14

Received: August 22, 2017; Accepted: September 12, 2017; Published: November 6, 2017

\begin{abstract}
The concepts of Industry 4.0 currently challenge manufacturing companies in various divisions such as purchasing, production, intralogistics, sales and human. Therefore, there is great need for a systematic approach to develop and implement industry 4.0 strategies. However, companies show different maturity levels concerning new technologies, processes and organizational aspects. This paper introduces a procedure model enabling companies to analyse their individual maturity level, to identify their own targets and to develop a specific action plan for implementation with an interdisciplinary team. A detailed theoretical as well as practical perspective is given for the procedure model for the field of action human. First application results for an Austrian company are presented showing that organizational changes within this field are still a bottom up driven process instead of a management indicated holistic change process.
\end{abstract}

Keywords: Industry 4.0, Roadmap Industry 4.0, Procedure Model, Capability Maturity Model

\section{Introduction}

Due to volatile and fast moving markets, increasing competition as well as more complex products and production, industrial companies are facing increasingly intricate challenges. Experts are talking about the fourth industrial (r)evolution, also called Industry 4.0 (I4.0). I4.0 focuses on an intelligent and transdisciplinary world in which smart factories represent the connection between digital and physical production networks. This development confronts companies with various challenges, in particular the pressure to strongly increase the level of digitization, to adapt production lines to new technologies or to define the role of humans within new processes.

Due to these demands there is a great need for a systematic approach to introduce I4.0 in enterprises respectively for a tool indicating the maturity level. Recently, there have already been presented some approaches in the literature. The most transparent and detailed I4.0 readiness model IMPULS - Industrie 4.0 Readiness [1] has been developed respecting six dimensions: strategy and organisation, smart factory, smart operations, smart products, data-driven services and employees. The readiness level is measured based on pre- defined target requirements used for all self-assessing companies. The maturity model for assessing industry 4.0 readiness in the domain of discrete manufacturing [2] is based on 62 maturity items in technological as well as organizational aspects. Expert knowledge has been applied to gain weighting factors for the assessment of these items. However, no identification of individual targets with comparison to actual performance is conducted within the two papers. In Merz [3] a 3-step concept is presented to develop the individual I4.0 strategy including the analysis, the determination of the company's aim with target requirements and the resulting action steps. Therefore, the three components competitor, the customer, and the company itself are respected. Other concepts are the seven-step migration model of Bildstein \& Seidelmann [4] or the maturity model of Jodlbauer \& Schagerl [5].

The proposed approach within this work is not to apply a general rigid assessment but to enable companies to develop their individual transformation process which is important in order to identify, evaluate and utilize the specific I4.0 potentials of the respective company. The proposed Industry 4.0 Roadmap has been developed in cooperation with a renowned Austrian company aiming at a structured and 
individual application of Industry 4.0 actions in industrial companies. Special focus within this paper is put on the relevance of human, additionally required competences and their role within new processes.

For the development of the 6-step I4.0 Roadmap a top down - bottom up - approach has been used. The core of the roadmap consists of maturity models covering the fields of purchasing, production, intra-logistics, sales and human. The maturity assessment is carried out by evaluating the different maturity levels within Microsoft Excel and is therefore easy to apply from the technical point of view. The six steps include general I4.0 analysis, a maturity analysis, the determination of the target state, development, and evaluation of measures for each field of action as well as the transfer of the target objectives and measures to a Balance Scorecard. Finally, the specific roadmap is determined. However, the I4.0 strategy must be defined and supported by the management, which is responsible for the initiation of I4. 0 activities.

Within this paper the results for the field of action human are given. The introduced model has already been successfully applied at a company. The results of the internal evaluation are presented in the form of a network graph. With the development of a structured Roadmap a framework has been created, which allows companies to evaluate main areas of activity concerning their I4.0 maturity and to derive desired target conditions. The maturity model targeting employees is comprehensive across all fields of activity and covers necessary competences and organizational requirements. In order to give deeper insight in the model, this paper deals with results of the self-evaluation in the field of human regarding their I4.0 maturity.

The structure of the remaining paper is organized as follows: In section Procedure Model a short literature review and the concept of the Roadmap Industry 4.0 is given. Section two focuses on the theoretical procedure model for the field of Human Resources (HR). In section three the individual results for the reference company are presented showing the application of the proposed Roadmap Industry 4.0 for this field of action before the paper closes with the conclusion.

\section{Method}

\subsection{Procedure Models}

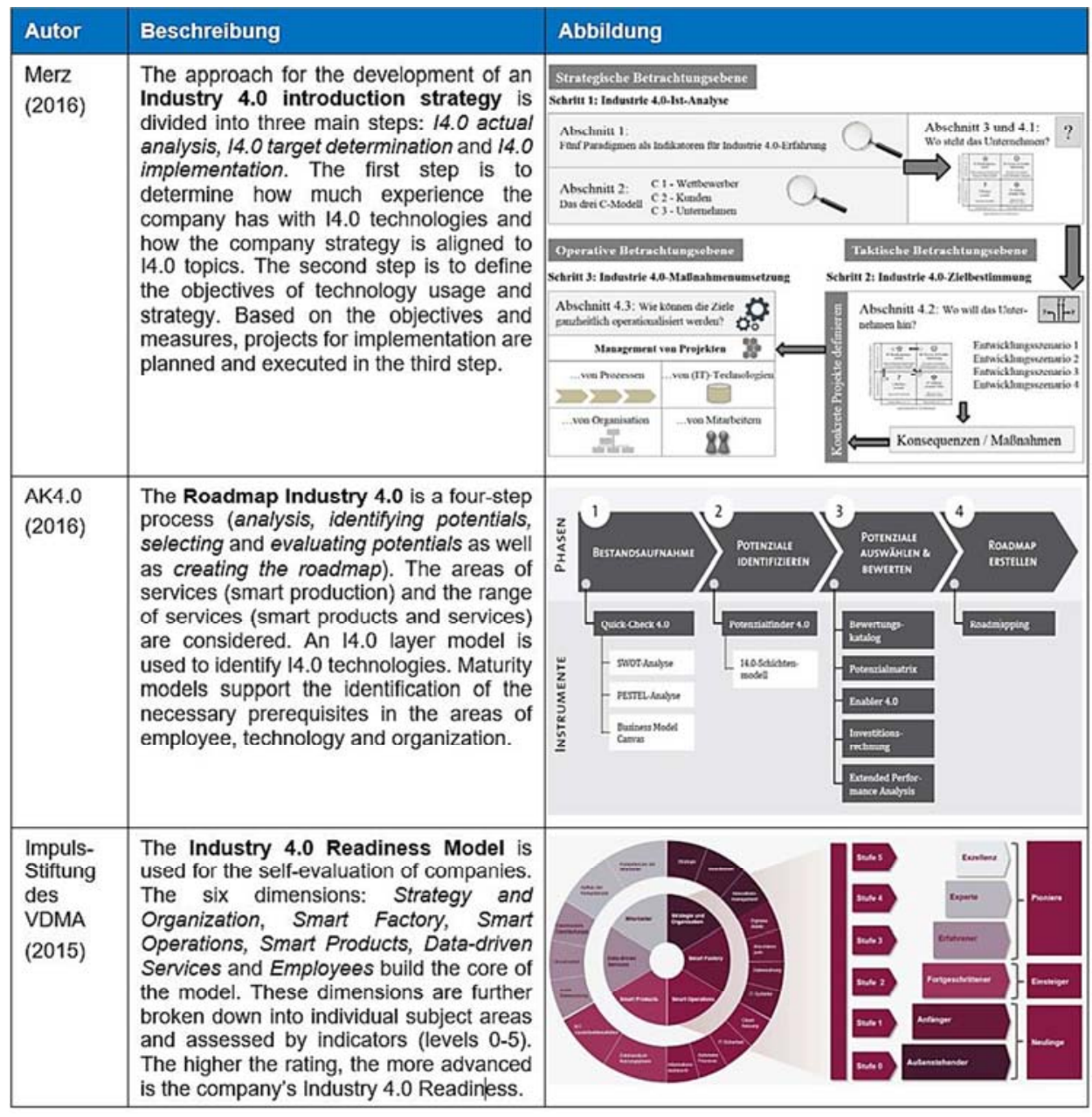

Figure 1. Capability maturity-and procedure models. 
Capability maturity models support companies in estimating their current situation regarding an examined field of action and consist of several criteria which are divided into dimensions (e.g., product, departments). Each criteria are described by different grades (degrees of maturity). Wellknown capability maturity models from other disciplines are the European Foundation for Quality Management (EFQM), Process and Enterprise Maturity Model [6], and the Capability Maturity Model Integration (CMMI). Capability maturity models can be used as a kind of benchmark, where organisations can evaluate their business processes or field of action relative to the maturity of other business processes in their market segment.

In contrast, procedure models support companies for the implementation of concrete projects by defining the steps forward to achieve a goal. The overall task is divided into individual, small process steps - for instance conducting an actual analysis, determining the target status and deriving the measures. This reduces the complexity as well as the planning and controlling of a project. Additionally, procedural models also build the framework for using methods and tools in the individual phases of the implementation process [7]. Capability maturity models can be used isolated or embedded in a procedure model for implementing industry 4.0 intentions [1] [8] [9] [10].

For using capability maturity models in company practice, a methodical approach is of great importance: the proposed model uses a five-step scale for the maturity rating of industry 4.0 , whereby level 1 is the basis and level 5 is the maximum maturity level. Each of these maturity levels includes criteria to be met in order to reach the level.
Companies can determine their degree of maturity by means of a self-assessment, by representing the existing level for each criteria. The higher the level of the individual criteria, the higher the degree of maturity in a company [11]. Figure 1 shows an extract of maturity- and procedure models for selfevaluation and implementation guides of industry 4.0.

The approaches described in Figure 1 differ in scope (capability maturity or procedure model), approach (phases) and also focus areas (technology, strategy and processes). A general concept is not applicable for the implementation of industry 4.0 in companies. An individual transformation process and approach is required in order to identify, evaluate and exploit the specific industrial potentials [12].

\subsection{Roadmap Industry 4.0}

The impact of the potential technological and organizational changes has prevented many companies generating an explicit industry 4.0 strategy or even systematically investing in industry 4.0 capabilities. The following reasons have been given why the potential of Industry 4.0 is not used - especially in the digitization of the vertical (company-specific) value chain and the horizontal integration between companies in the supply chain [13]:

a. High investment costs due to a lack of industry 4.0 suitability of the existing production infrastructure,

b. Missing transparency or quantifiability of the benefits of industry 4.0,

c. Concerns about organizational changeability and ITsecurity.

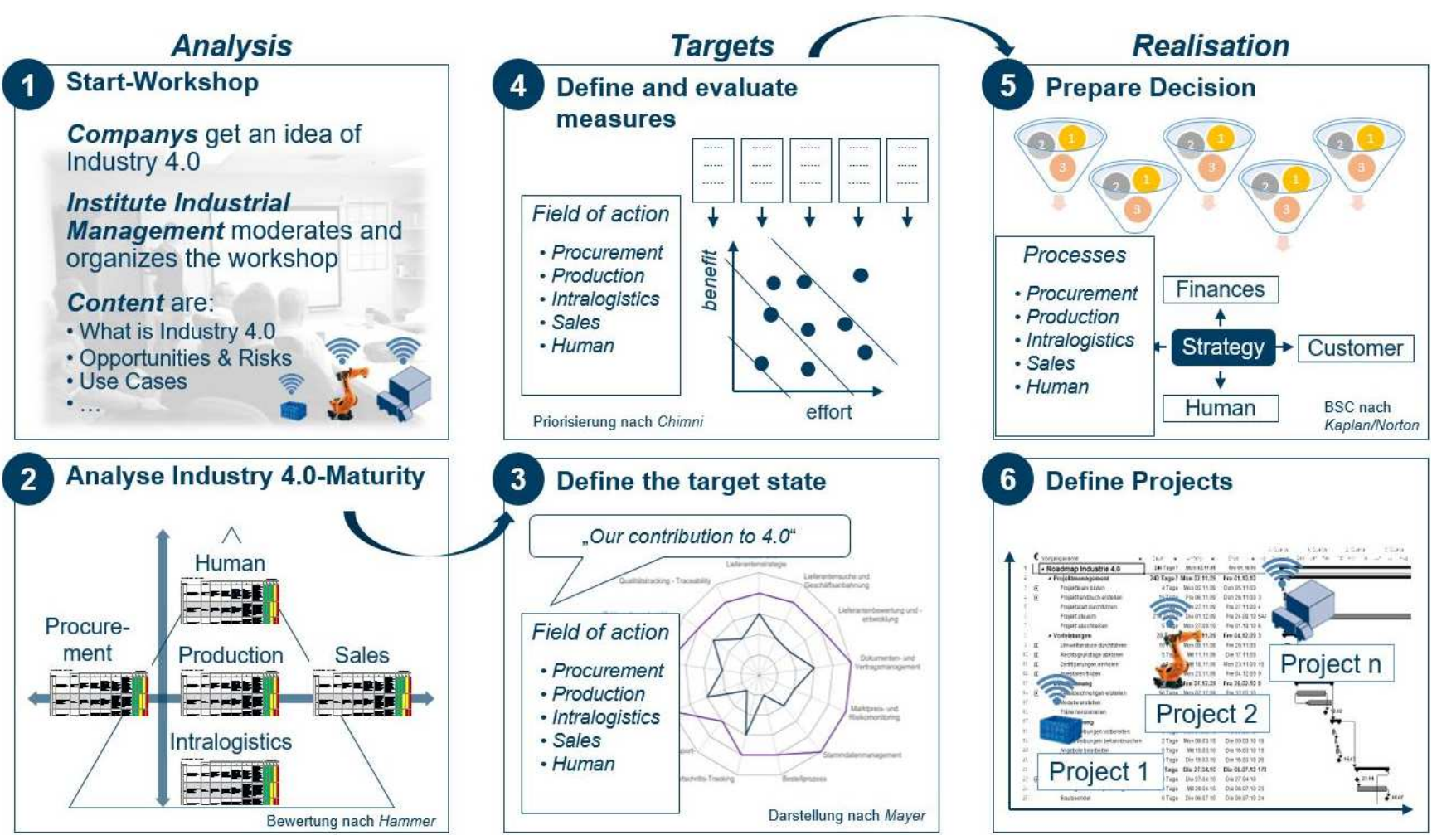

Figure 2. Roadmap Industry 4.0. 
Therefore, the Institute Industrial Management of $\mathrm{FH}$ JOANNEUM University of Applied Sciences developed together with an internationally renowned industrial company a Roadmap for the implementation of Industry 4.0 (see Figure 2) in an applied research project. The developed procedure model (Roadmap Industry 4.0) contains three major phases: analysis, goal setting and implementation. It is divided into 6 steps which will be passed sequentially. This ensures a systematic identification of the current maturity of Industry 4.0 and the existing competences as well as the definition of targets. The roadmap is at the same time basis for self-assessment and guide for implementation of an industry 4.0 strategy.

The developed Roadmap Industry 4.0 addresses five areas: purchasing, production, intralogistics, sales and human resources The areas are derived from the approach of the value-stream analysis, which takes these key business areas into account [14]. In the fields of action itself, the focus is placed on internal vertical IT- and cross-company horizontal IT-integration. Also customers and suppliers, who are affected by the realization of an industry 4.0 project, have to be informed and integrated at an early stage of the expected changes.

The roadmap represents a bottom-up approach, in which the specialists of the corresponding fields analyse the actual state as well as independently define the present maturity as a part of the company's strategy. The five capability maturity models allow the individual and flexible view of the company. Thus, in the transformation process, individual selected areas can be taken into consideration or all five action fields can be processed simultaneously.

The following norm strategies are recommended for companies that have not yet defined their industry 4.0 targets [13]:

a. Norm Strategy 1: Lean processes (Lean Management as a prerequisite for digitization and generally for industry 4.0)

b. Norm Strategy 2: Invest in digitalisation in all areas of the company (IT as prerequisite for industry 4.0 and especially for new business models)

c. Norm Strategy 3: To promote the necessary know-how of the employees to exploit the potential of lean management and digitization (motivated and competent employees as an enabler of Industry 4.0

The above-mentioned fields of action and the defined norm strategies automatically result in a higher digital maturity which is the prerequisite for (new) digitized business models.

Following the determination of the target states, the necessary measures for the implementation are derived. Then the measures will be evaluated concerning costs and benefits, selected and included in a Balanced Scorecard [15]. Finally, the individual roadmap for the company will be defined - that means, the chronological sequence of the planned measures in the form of concrete projects.

\subsection{Structure of the Roadmap}

In Step 1 it is important to create awareness for industry 4.0 in the company (involved employees). A start-workshop is intended to generate an impulse by presenting the essential content, concepts and technologies of industry 4.0. The workshop also includes a steadily growing collection of industry 4.0 use cases to help companies to demonstrate the practical realisation of $\mathrm{I} 4.0$ technologies and making the issue more tangible. Furthermore, it is important to demonstrate the resulting benefits through the use of (new) technologies (e.g. intelligent, smart products) for companies.

In the start-workshop companies have to define the scope of the planned industry 4.0 project - the number of fields of action (Step 2) as well as to announce the employees which are involved in the change process. Also the opportunities and threats (external view) of industry 4.0 as well as strengths and weaknesses (internal view) will be elaborated [16]. A SWOT (strengths, weaknesses, opportunities, threats) analysis, the results of the external company-environment analysis, is prepared in the form of a threat / opportunity catalogue and compared with the strength / weakness profile of the internal company analysis. The aim is to maximize the benefits of strengths and opportunities and to minimize the loss of weaknesses and threats [17].

Step 2 is about ascertaining the company's status and existing competences concerning industry 4.0. In each of the five developed capability maturity models for the fields of action (purchasing, production, intralogistics, sales and human) there are specific questions about strategic considerations and operational processes. There are defined five maturity levels which build on each other. Level 1 describes a state with low to no IT support and very ad hoc controlled processes. From level 3 onwards an Enterprise Resource System (ERP) is used as far as possible. The processes are structured and planned and it is not necessary to react ad hoc to events. On level 4, appropriate IT systems such as Supplying Relationship Management (SRM) for purchasing, Manufacturing Execution System (MES) for production, Customer Relationship Management (CRM) for sales, and Warehouse Management System (WMS) for intralogistics are used. Level 5 represents the highest level - a partial yet visionary approach based on possible technologies of industry 4.0.

Due to the fact that industry 4.0 is a long-term development process and future technological developments cannot be predicted, the capability maturity models describe a current state of this development. Therefore, it will be necessary to enhance level 5 in the future and to reduce the existing levels by one step. That means, the current level 5 will describe level 4 in future [10]. It is of relevance to evaluate the maturity levels sufficiently realistic in order to pick up companies and to show possible development paths of industry 4.0. In practice, certain requirements are fulfilled only partially or requirements are not fully implemented throughout the entire company. For this reason, Hammer 's evaluation logic is applied [6]: This means, that the maturity level is fulfilled with more than $80 \%$ realisation degree, between $20 \%$ and $80 \%$ as a partial, and less than $20 \%$ as not fulfilled.

In Step 3, the target state for each field has to be defined. Within the company's industry 4.0 strategy, interdisciplinary 
expert teams discuss in workshops which future target states must be achieved. The capability maturity model of each field of action determines the desired states, by defining a target maturity level for each criteria. Level 5 does not have to automatically represent the desired target state. Due to company's specific priorities and structures, lower maturity levels also can fulfil the requirements of the field of action.

Based on the defined target profiles, in Step 4 it is necessary to derive, document and evaluate concrete measures in order to determine the difference between the actual and the target maturity level. Measures can be derived directly from the maturity levels or must be determined if necessary. For this, creativity techniques such as brainstorming and writing, morphological analysis or method $6|3| 5$ are offered [18]. Then the measures are evaluated concerning effort $(0 \ldots$ low $-6 \ldots$ high $)$ and benefit $(0 \ldots$ low $6 \ldots$ high) and are described with the estimated costs. This makes quick wins easy visible - measures that achieve a high benefit with little effort [8], [12], [16].

In Step 5, the defined objectives (target profile) and measures regarding relevance and contribution to the company strategy are selected. Subsequently, the selected objectives and measures are transferred to a Balance Scorecard (BSC), supplemented by key figures and concrete measurable targets for the review of the implementation [19].

In the last Step 6 of the procedure model, concrete industry 4.0 implementation projects are defined and connected with budgets. It is advisable to start with pilot projects and to incorporate the gained experiences into the next planning and implementation purposes. Problems arising during rollout can be identified and remedied at an early stage. In addition to cost/benefit assessments, these experiences are important for the planning of future industry 4.0 projects [4].

It is important to mention that the rapid progress of digitalization does not only influence production and manufacturing. Nearly all departments can potentially benefit from a greater degree of digitalization. As an interface responsible for all employees within the company, Human Resources (HR) is particularly challenged by the drafted changes. The following chapter deals with aspects of future work resulting from digitalization and discusses the impact of the fourth industrial (r)evolution on the current labour market.

\subsection{Capability Maturity Model Human}

The capability maturity model Human was conducted in order to underline the position and relevance of humans as a central component in industry 4.0 [20]. The field of action is across the board and covers necessary competences and organizational requirements regarding digitalization. Thus, Human Resources (HR) is not only a separate department but influences all parts within a company. As pointed out, the capability maturity model addresses different areas of development in the field of HR and includes five levels of maturity each. The individual areas are derived from the strategic HR approach of Ryschka (see Figure 3) [21]. However, the individual process steps have been further specified in order to fit practical needs [22].

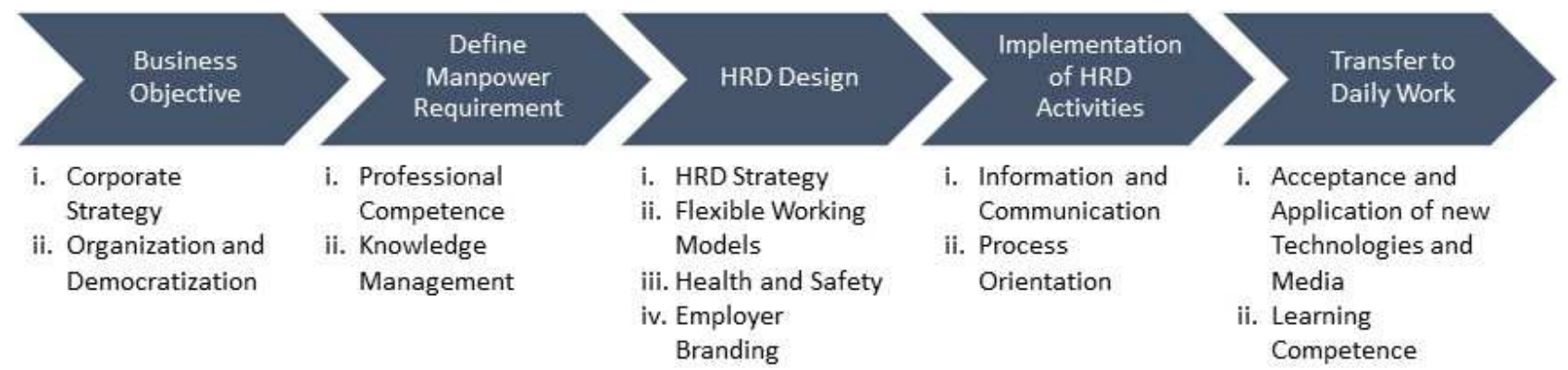

Figure 3. Areas of Development in the field of Human Resources.

As pointed out, digitalization affects every area within a company beginning with the business objective and down to the daily work. Thus digitalization must be included within the corporate strategy. Also changes of organizational structures might be necessary hence hierarchical organizational structures and a lack of democratization within the company influence the development negatively [23].

Due to the outlined strategic HR approach (see Figure 3), in the second step the required manpower must be defined. Therefore, it is not enough to describe the necessary competencies. A distinct knowledge management should also be present at this point in order to secure systematization [24]. In terms of digitalization companies perceive effective, sustainable HR planning rather complex as it is not yet clear which new competencies future jobs will require. It is only agreed that interface activities and control tasks will gain in importance [20]. Due to this development, abilities such as problem solving, (Big) data analysis, transformation of business models or personal competences like humanmachine-communication are significant [22], [25], [26].

Especially regarding digitalization, Human Resource Development (HRD) is a main issue to reduce the inhibition level of the employees and to support them in the change process. This third step should be characterized by a transparent, open communication culture and adapted to the individual needs of the employees. These criteria are important not only regarding further development content but also in terms of working models or healthy and secure workplaces [22].

Implementing the planned HR activities is the next process step. Therefore, clear internal information through formal and informal communication paths is a key success factor. 
Furthermore, process orientation secures an efficient systematic approach [22].

A successful long term implementation of the developed measures can be reached by integrating the improvement into the daily workflow. This can only be achieved by generating broad acceptance among the employees regarding the necessity of digitalization. Continuous improvement respectively the willingness for continuous learning favours consistency [27], [28]. The outlined strategic HRD process is accompanied by an evaluation process. Ongoing reflection enables the company to detect potentials for improvement which directly influences the individual degrees of maturity within the outlined industry 4.0 maturity model [21]. Thus, necessary actions can be taken in order to achieve an even higher degree of maturity [22].

\subsection{Guiding Questions and Maturity Levels}

Every outlined area of development is specified by a leading question and some key criteria. This defines the orientation of the topic and delineates the goal of the dimension. Based on those guiding questions maturity levels were defined for all dimensions in the field of action. As described above, the company has to ascertain its actual maturity by defining the level and the percentage of completion. The circle symbolizes whether the level is accomplished to a large (full), mediocre (half) or little (blank) extent. The target maturity level always stands for a degree of fulfilment of more than $80 \%$, which would correspond to a green colouring. Two areas of development are described in more detail below.

Corporate Strategy

Regarding the strategic HRD process, special attention should be paid at the company strategy. Therefore the guiding question is: Is Industry 4.0 considering the corporate strategy which can be described by key criteria such as Integration of 14.0 or Implementation.

Table 1. Maturity levels regarding Corporate Strategy with exemplary maturity.

\begin{tabular}{lll}
\hline $\begin{array}{l}\text { Maturity } \\
\text { level }\end{array}$ & Maturity level definition \\
\hline 1 & Industry 4.0 is not considered in the company strategy at all. A dispute does not take place. \\
2 & Industry 4.0 is not considered in the company strategy. However, the company has begun to deal with industry 4.0. & $\begin{array}{l}\text { Actual } \\
\text { maturity } \\
\text { level } \\
\text { maturity } \\
\text { level }\end{array}$ \\
4 & Industry 4.0 attracts moderate attention in the company strategy. The formulation of an industry 4.0 strategy has \\
5 & just begun. Measures are implemented in some areas. & \\
Industry 4.0 attracts considerable attention in the corporate strategy. Measures are implemented by a majority.
\end{tabular}

The five levels shown in Table 1 depict the degree of I 4.0 integration. The lowest maturity level is equal to no industry 4.0 reference, the highest represents full integration including a systematic measurement system.

The integration of industry 4.0 into the company strategy is an important success factor for the change process. The company must act actively and be clearly responsible for the change. Doing so, the decision-makers act as multipliers to create awareness and a wide acceptance among the employees [29]. For this reason, a high degree of maturity should be sought quickly in this dimension.

Organization and Democratization

The second dimension that shapes the whole company in terms of industry 4.0 is addressing the organizational structure as well as the democratization and answers the question: How is the company organized? Key issues are the organizational model and hierarchy, the decision-makingprocesses and leadership.

Table 2. Maturity levels regarding Organization and Democratization with exemplary maturity.

\begin{tabular}{|c|c|c|c|}
\hline $\begin{array}{l}\text { Maturity } \\
\text { level }\end{array}$ & Maturity level definition & $\begin{array}{l}\text { Actual maturity } \\
\text { level }\end{array}$ & $\begin{array}{l}\text { Target maturity } \\
\text { level }\end{array}$ \\
\hline 1 & $\begin{array}{l}\text { Rigid hierarchies and many hierarchical levels. Organization in separate departments (little } \\
\text { networking) with high bureaucracy. Long decision processes. Authoritarian leadership (no } \\
\text { employee participation) and no established leadership culture. }\end{array}$ & & \\
\hline 2 & $\begin{array}{l}\text { Organization in departments were networking takes place unsystematically. High bureaucracy } \\
\text { with long decision-making processes whereas processes are shortened by clear substitution } \\
\text { rules. Patriarchal/informative leadership style with partial co-determination of employees. } \\
\text { Hence the leadership culture is not yet established. }\end{array}$ & & \\
\hline 3 & $\begin{array}{l}\text { Corporate structures become flatter and there are first approaches of process orientation. Also } \\
\text { project teams are built occasionally. Co-operative leadership with first approaches to a feedback } \\
\text { culture. Employees have the possibility to co-determine their tasks and targets. All in all a } \\
\text { leadership culture is available and is also lived as such. }\end{array}$ & ( & 3 \\
\hline 4 & $\begin{array}{l}\text { Flat hierarchies favour the self-organization of employees which means there is a clear focus on } \\
\text { processor orientation. An increased use of project teams and possible responsibility allows } \\
\text { employees to make quick decisions (participatory leadership style). New managers are selected } \\
\text { by their leadership style, which is adapted to the existing management culture. }\end{array}$ & 0 & \\
\hline 5 & $\begin{array}{l}\text { Corporate organization relies on open, flexible and self-organizing network structures with } \\
\text { maximum possible decision-making power of the employees in clearly defined areas. Also there } \\
\text { are substitute deputations at the lowest level of staff to ensure rapid reaction times. }\end{array}$ & 0 & \\
\hline
\end{tabular}


The possibility of real-time control of fully digitalized companies and the associated new areas of competence also require flexible organizational structures [20]. The named organizational changes must go hand in hand with the entire change process. Unlike the anchoring of I4.0 in the company strategy, it is not possible to convert this without the appropriate adaptation of the working processes. Nevertheless, it is important to make the necessary preparations for the adaptation. Also particularly cultural changes, such as those of the leadership or communication culture, can only be realized over an extended period of time.
Just implementing measures is not sufficient [29].

\section{Results}

\subsection{Gap Analysis}

In total, the capability maturity model Human has 13 areas of development that must be evaluated in order to get a holistic overview. Based on this, a target maturity level can then be derived for each area. Table 3 shows how a fully completed maturity model can look like.

Table 3. Maturity levels regarding Corporate Strategy with exemplary maturity.

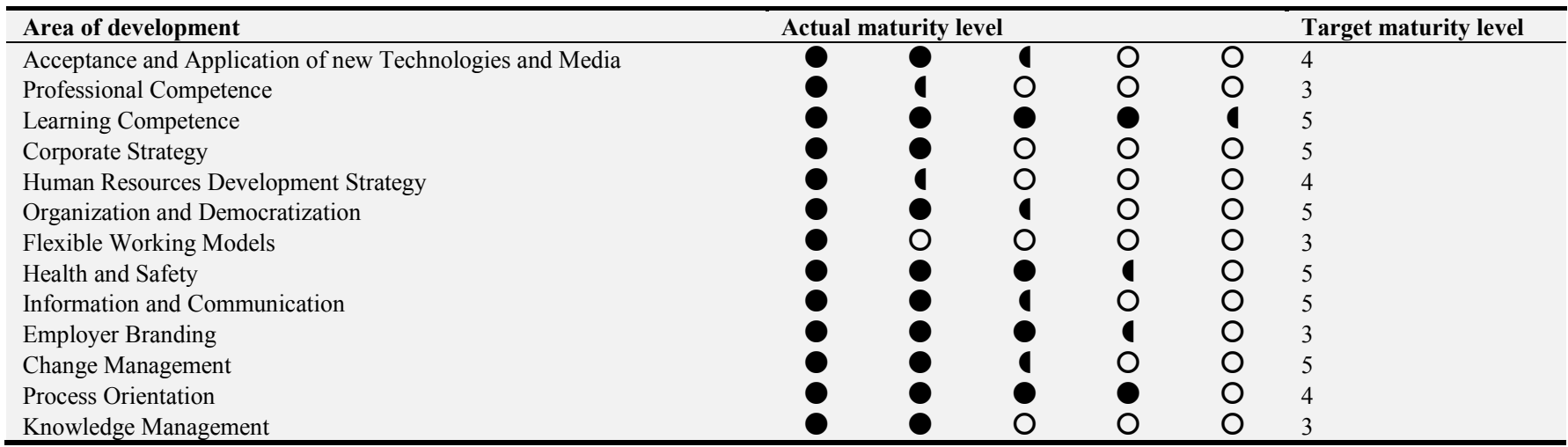

As described above, green represents a degree of completion greater than $80 \%$, yellow between $20 \%$ and $80 \%$, and red for less than $20 \%$. In addition to the actual values, each company defines individual target maturity levels. Based on this, development measures can be derived within step 4 of the Roadmap Industry 4.0. In order to better visualize the need for action, both actual and target maturity level are combined within a spider chart as can be seen in Figure 4.

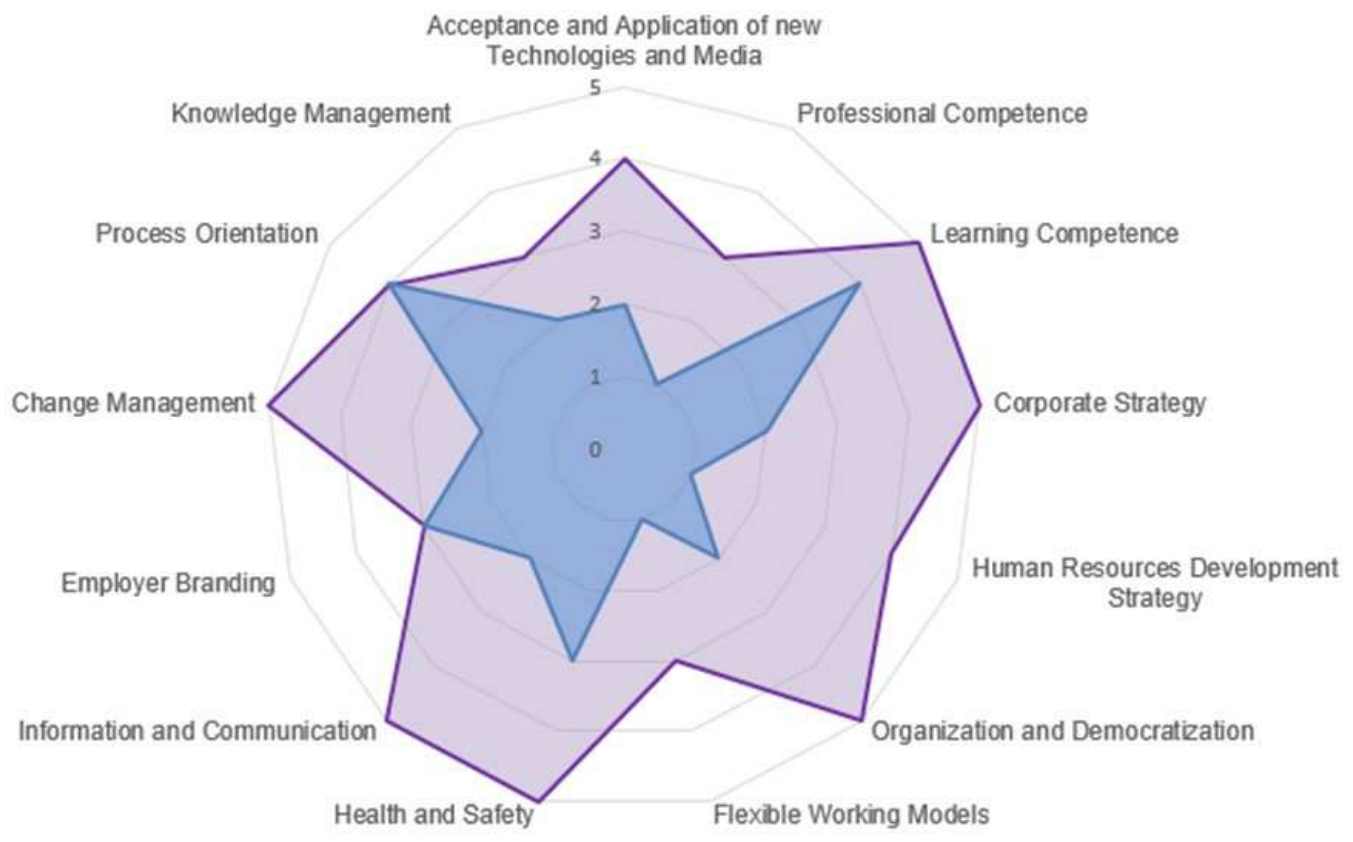

口Target 口Actual

Figure 4. Actual and Target Maturity Level Simulation. 
For the actual values, always the level with the highest degree of maturity is used, which means the one that has a maturity of more than $80 \%$. The blue field shows the current situation in a simulated company, the violet field represents the desired maturity. At a glance it becomes clear that the company generally has a low industry 4.0 maturity, so it is only at the beginning of the development process. Some dimensions are to be expanded strongly (for example, the HRD strategy), regarding some factors the company has already reached the required maturity (for example with respect to processor orientation).

\subsection{Evaluation of the Capability Maturity Model Human}

As stated before, the Industry 4.0 roadmap was developed within an industry project by the Institute Industrial Management of FH JOANNEUM University of Applied Sciences and an internationally renowned industrial company. After working out the various dimensions and maturity levels, the company also did a pretest to figure out whether the determination of the current degree of maturity can practically be made. The classification of the capability maturity model Human could be done within a half day workshop without comprehension problems. The following figure shows the current maturity level of the company for every defined criteria.

After a company has detected its actual maturity level, a decision about the dimensions to be further developed in order to reach a higher level of maturity has to be made. Defining such a digitalization strategy should follow systematic strategy processes and demands an intensive discussion with industry 4.0. As one can see in Figure 5 within the pre-test the company defined itself on maturity level 2 in terms of the corporate strategy. Thus, the company has only begun to deal with industry 4.0 so far, for what reason it was not possible to define the target maturity level within the same workshop.

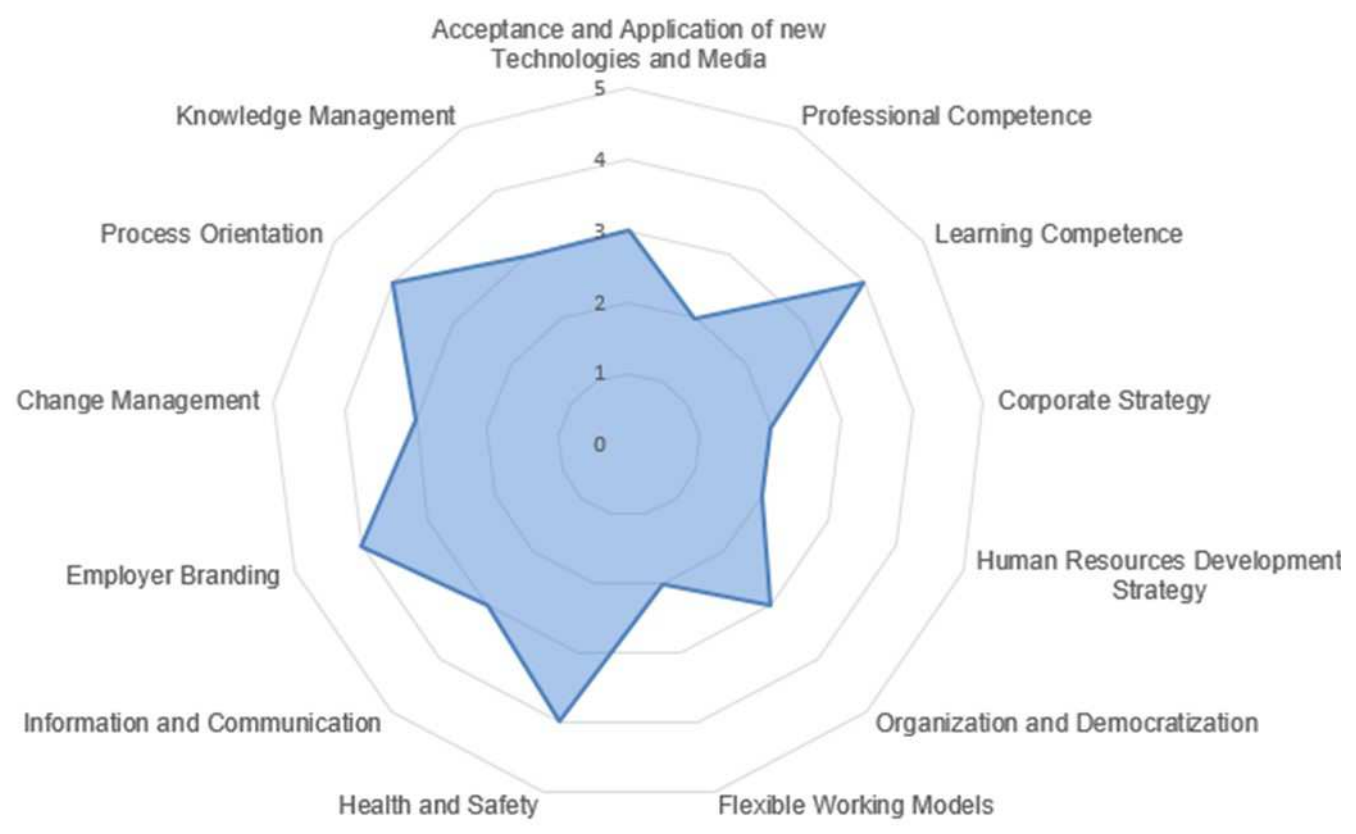

Figure 5. Actual Maturity Level.

In general, the I 4.0 maturity of the company is located at an average maturity of 3 . Organizationally the company is already well prepared for I 4.0: Processor orientation is strongly developed and first approaches of corporate democracy as well as shortened decision-making-processes are given.

\section{Discussion}

Nevertheless, there seems to be uncertainty about the increasing digitalization. This is shown primarily by the fact that the expected changes in the company's activities cannot yet be estimated (only maturity level 2 in the field of professional competence). A systematic holistic change process is also not established, which explains the low level of information and communication maturity. In addition, there is no top down approach regarding industry 4.0 as it is not part of the corporate strategy. This leads to problems of acceptance and a disparity in the degree of digitization in the company, some departments are more digitalized than others.

Despite those weaknesses, the company has great potential: The willingness to learn and the framework where learning takes place are above average. Relevant further training measures such as e-learning or seminars are provided internally as well as externally for the employees and can be consumed after individual approval. Therefore, the company provides necessary learning material as well as equipment such as electronic devices or study areas. Furthermore, the employees actively influence the company's further development program.

Summing up, the high maturity in willingness to learn points to a learning organization. If such a learning culture is 
anchored in the company, it is easier to achieve the necessary acceptance for the change and to successfully increase the degree of digitalization. However, this is only possible if the entire company represents the reorientation. Without the exemplary role of management, such a comprehensive transformation is hardly possible.

\section{Conclusion}

The proposed paper introduces a six-step Roadmap Industry 4.0 applicable for a set of five fields of actions (purchasing, production, intralogistics, sales and human). The procedure model consists of a first introduction on industry 4.0 , the analysis of the industry 4.0 maturity level of the company and the definition of the company's specific targets. The comparison of required and actual state allows developing an individual plan of action for each focused field of action as well as the transfer of the objectives and measures to a Balance Scorecard.

This paper provides detailed insight to the procedure for the field human. Theoretically relevant information as well as the systematic application of the procedure model within an Austrian company is transparently given. First results show that the procedure model is easy to use. However, two main challenges could be identified: Since the field of human is especially extensive and affects the entire company, people of different divisions should ideally be included in the maturity assessment process. Secondly, the definition of the target requirements and the implementation of the final action plan become especially challenging if industry 4.0 has not yet been an embedded part of the overall strategy.

Summarized, the Roadmap Industry 4.0 is a suitable tool for a systematic establishment or improvement of the individual multi-disciplinary I4.0 strategy in order to increase the overall I4.0 maturity.

\section{References}

[1] Lichtblau, K., Stich, V., Bertenrath, R., Blum, M., Bleider, M., Millack, A., Schmitt, K., Schmitz, E., Schröter, M., (2015), Industrie 4.0-Readiness, Aachen, Köln.

[2] Schumacher, A., Erol, S., Sihn, W., (2016), A Maturity Model for Assessing Industry 4.0 Readiness and Maturity of Manufacturing Enterprises. Procedia CIRP, 52, pp. 161-166.

[3] Merz, S. L., (2016), Industrie 4.0-Vorgehensmodell für die Einführung. In: Roth, A., (Edt.): Einführung und Umsetzung von Industrie 4.0, Berlin/Heidelberg, pp. 83-110.

[4] Bildstein, A., Seidelmann, J., (2014), Industrie 4.0-Readiness: Migration zur Industrie 4.0-Fertigung. In: Bauernhansl, T., ten Hompel, M. and Vogel-Heuser, B., (Edt.): Industrie 4.0 in Produktion, Automatisierung und Logistik, pp. 580-597. Wiesbaden: Springer Vieweg Verlag.

[5] Jodlbauer, H., Schagerl M., (2016), Reifegradmodell Industrie 4.0-Ein Vorgehensmodell zur Identifikation von Industrie 4.0 Potentiale, INFORMATIK 2016 Lecture Notes in Informatics (LNI), Klagenfurt, Österreich, pp. 1473-1488.
[6] Hammer, M., (2007), The Process Audit. Harvard Business Review, April, pp. 111-123.

[7] Leimeister, J. M., (2012), Dienstleistungsengineering und management. Berlin/Heidelberg: Springer-Gabler-Verlag.

[8] Bechtold, J., Kern, A., Lauenstein, C., Bernhofer, L., (2014), Industry 4.0-The Capgemini Consulting View-Sharpening the Picture beyond the Hype.

[9] Feld, T., Hoffmann, M., Schmidt, R., (2012), Industrie 4.0Vom intelligenten Produkt zur intelligenten Produktion. In: IM Information Management und Consulting, March, pp. 3842 .

[10] VDMA Forum Industrie 4.0 (2015), Leitfaden Industrie 4.0 Orientierungshilfe zur Einführung in den Mittelstand, VDMA Verlag, Frankfurt am Main: tredition $\mathrm{GmbH}$.

[11] Allweyer, T., Knuppertz, T., (2009), EDEN-Reifegradmodell für Prozessmanagement: Prozessorientierung in Unternehmen, White Paper, Deutschland.

[12] Seiter, M., Bayrle, C., Berlin, S., David, U., Rusch, M., Treusch, O., (2016), Roadmap Industrie 4.0-Ihr Weg zur erfolgreichen Umsetzung von Industrie 4.0, Hamburg.

[13] Tschandl, M., Mallaschitz, C., (2016), Industrie 4.0: Controller als Treiber einer strategischen Neuausrichtung. In: Der Controlling-Berater, 43, pp. 85-106.

[14] Erlach, K., (2010), Wertstromdesign-Der Weg zur schlanken Fabrik, Berlin: Springer Verlag.

[15] Kaplan, R. S., Norton, D. P., (1997), Strategien erfolgreich umsetzen, aus dem Amerikanischen von Horváth, P., KuhnWürfel, B. and Vogelhuber, C., Stuttgart: Schäffer-Poeschl Verlag.

[16] Rusch, M., Treusch, O., David, U., Seiter, M., (2016), Industrie 4.0 - Controllers Aufgaben. In: Controller Magazin, 3, pp. 70-79.

[17] Springer Gabler Verlag, (2017), Gabler Wirtschaftslexikon, [13. February 2017].

[18] Higgins, J. M., Wiese, G., (1996), InnovationsmanagementKreativitätstechniken für den unternehmerischen Erfolg, Berlin-Heidelberg: Springer Verlag.

[19] Horváth \& Partner (Edt.), (2001), Balanced Scorecard umsetzen, 2. Auflage, Stuttgart: Schäffer-Poeschl Verlag.

[20] Spath, D., Ganschar, O., Gerlach, St., Hämmerle, M., Krause, T., Schlund, S., (Edt.), (2013), Studie Produktionsarbeit der Zukunft-Industrie 4.0, Fraunhofer, Stuttgart.

[21] Ryschka, J., Solga, M., Mattenklott, A., (2011), Personalentwicklung: Gegenstand, Prozessmodell, Erfolgsfaktoren. In: Ryschka, J., Solga, M. and Mattenklott, A., (Edt.): Praxishandbuch Personalentwicklung: Instrumente, Konzepte, Beispiele, pp. 19-30. Wiesbaden: Gabler.

[22] Sorko, S. R., Rabel, B., Richter, H. M., (2016), The Future of Employment-Challenges in Human Resources through Digitalization. In: International Scientific Journal Industry 4.0, 2/2016, pp. 128-131.

[23] Ittermann, P., Niehaus, J., Hirsch-Kreinsen, H., (2015), Arbeiten in der Industrie 4.0. Trendbestimmungen und arbeitspolitische Handlungsfelder. Dortmund: Hans-BoecklerStiftung. 
[24] Leinweber, S. (2013), Kompetenzmanagement. In: Meifert, M., (Edt.), Strategische Personalentwicklung: Ein Programm in acht Etappen, pp. 145-178. Wiesbaden: Springer Gabler.

[25] Botthof, A., Hartmann, E. A., (Edt.), (2015), Zukunft der Arbeit in Industrie 4.0. Berlin: Springer Vieweg.

[26] World Economic Forum, (2016), The Future of Jobs. Employment, Skills and Workforce Strategy for the Fourth Industrial Revolution,

$\mathrm{http} / / / \mathrm{www} 3$.weforum.org/docs/WEF_Future_of_Jobs.pdf, [10 März 2017].
[27] Becker, M., (2011), Systematische Personalentwicklung: Planung, Steuerung und Kontrolle im Funktionszyklus. Stuttgart: Schäffer Poeschl.

[28] Tschumi, M., (2014), Praxisratgeber zur Personalentwicklung. Zürich: Praxium.

[29] Lauer, T., (2014), Change Management. Grundlagen und Erfolgsfaktoren, 2. Auflage, Aschaffenburg: Springer Gabler. 